University of Nebraska - Lincoln

DigitalCommons@University of Nebraska - Lincoln

Virology Papers

Virology, Nebraska Center for

2005

Dichotomy in Cross-Clade Reactivity and Neutralization by HIV-1

Sera: Implications for Active and Passive Immunotherapy

\author{
Lisa A. Cavacini \\ Harvard Medical School, Icavacin@bidmc.harvard.edu \\ Mark Duval \\ Beth Israel Deaconess Medical Center \\ Ajay Patil \\ Beth Israel Deaconess Medical Center \\ Charles Wood \\ University of Nebraska-Lincoln, cwood1@unl.edu \\ Kanneth H. Mayer \\ Brown University \\ See next page for additional authors
}

Follow this and additional works at: https://digitalcommons.unl.edu/virologypub

Part of the Virology Commons

Cavacini, Lisa A.; Duval, Mark; Patil, Ajay; Wood, Charles; Mayer, Kanneth H.; Ruprecht, Ruth M.; and Posner, Marshall L., "Dichotomy in Cross-Clade Reactivity and Neutralization by HIV-1 Sera: Implications for Active and Passive Immunotherapy" (2005). Virology Papers. 163.

https://digitalcommons.unl.edu/virologypub/163

This Article is brought to you for free and open access by the Virology, Nebraska Center for at DigitalCommons@University of Nebraska - Lincoln. It has been accepted for inclusion in Virology Papers by an authorized administrator of DigitalCommons@University of Nebraska - Lincoln. 


\section{Authors}

Lisa A. Cavacini, Mark Duval, Ajay Patil, Charles Wood, Kanneth H. Mayer, Ruth M. Ruprecht, and Marshall L. Posner 
Published in the Journal of Medical Virology 76: 146-152 (2005).

Accepted February 23, 2005. DOI: 10.1002/jmv.20339. Used by permission.

Copyright 2005, Wiley-Liss. Published online, Wiley InterScience (www.interscience.wiley.com).

Work was performed at Beth Israel Deaconess Medical Center, Boston, Massachusetts.

Grant sponsor: NIH; Grant numbers: AI26926, P01AI48240.

\title{
Dichotomy in Cross-Clade Reactivity and Neutralization by HIV-1 Sera: Implications for Active and Passive Immunotherapy
}

\author{
Lisa A. Cavacini ${ }^{1,2^{*}}$, Mark Duval ${ }^{1}$, Ajay Patil ${ }^{1}$, Charles Wood ${ }^{3}$, \\ Kenneth H. Mayer ${ }^{4,5}$, Ruth M. Ruprecht ${ }^{2,6}$, and Marshall R. Posner ${ }^{1,2}$ \\ ${ }^{1}$ Beth Israel Deaconess Medical Center, Boston, Massachusetts, \\ ${ }^{2}$ Harvard Medical School, Boston, Massachusetts, \\ ${ }^{3}$ University of Nebraska at Lincoln, Lincoln, Nebraska, \\ ${ }^{4}$ Fenway Community Health, Boston, Massachusetts, \\ ${ }^{5}$ Miriam Hospital/Brown University, Providence, Rhode Island, \\ ${ }^{6}$ Dana-Farber Cancer Institute, Boston, Massachusetts \\ * Correspondence to L. A. Cavacini: lcavacin@bidmc.harvard.edu
}

The identification of broadly reactive and cross-clade neutralizing antibodies will facilitate the development of a more universally effective vaccine for human immunodeficiency virus (HIV). Antibodies in sera from individuals infected with Clade B HIV bind native primary viral isolates, and virus binding correlates with neutralization and stable clinical disease. In this study, we quantified cross-clade antibody reactivity and neutralization by Clades B and C sera. Primary viral isolates were captured by serum IgG bound to anti-human IgG and quantitated as p24 released by lysis of captured virus. Neutralization was determined using PHA-stimulated PBMC. Clade B antibodies reacted more frequently with Clade B R5 virus, but positive sera captured quantitatively more $\mathrm{X} 4$ virus than R5 and R5X4 virus. Clade $\mathrm{B}$ sera reacted less frequently and captured less Clade $C$ virus than Clade B virus. Antibodies in Clade $C$ sera captured Clades B and $C$ isolates with equal frequency and quantity. There was no difference in neutralization of Clade B virus by either group of sera; however, Clade $C$ sera neutralized Clade $C$ virus, whereas Clade B sera were ineffective against Clade $C$ virus. Thus, there are distinct differences in cross-clade reactivity of and neutralization by antibodies induced in response to Clade C infection compared to Clade B infection. Understanding antibody responses to native virions after Clade $C$ infection and cross clade antibody behavior has implications for understanding pathogenesis and vaccine development.

KEY WORDS: human immunodeficiency virus; neutralization; serum antibody; cross-clade

\section{INTRODUCTION}

A major goal of human immunodeficiency virus (HIV) vaccine research is to develop an effective vaccine that is protective against all clades of HIV-1. Clade B virus predominates in North America and parts of Europe. Other clades are prevalent elsewhere in the world. Clade $\mathrm{C}$ virus constitutes a major fraction of infections in Southern and Eastern Africa, India, Nepal, and China. Clade C is endemic in parts of Africa where infection and transmission rates are very high [Essex, 1993; Oelrichs et al., 2000; Spira et al., 2003]. India and China have the potential to become a major factor in the epidemic in the future, and there are already more than 5 million Clade $C$ infections in India alone [Arora et al., 2004]. While there is minimal interclade diversity within the pol and gag region of HIV1 , there is considerable inter-and intra-clade variation in the env region. To date, a majority of the vaccines being tested are based on, or at least have as one component, the env region of HIV, based on Clade B isolates. A specific understanding of limitations of cross-reactive and subtype specific Env responses is required to maximize the development of a broadly effective HIV-1 vaccine.

While both cross-reactive and subtype-specific CTL responses, predominantly to gag and pol sequences, have been reported [Betts et al., 1997; Cao et al., 1997; Ferrari et al.,1997], the humoral response to vaccines and infections is directed towards Env, where more diversity is seen. Early reports suggested that there is no strict clade dependence of neutralization [Kostrikis et al., 1996; Moore et al., 1996; Nyambi et al., 1996; Weber et al., 1996]. It was shown that while sera from Clades B and E patients pref- 
erentially reacted with monomeric gp120 from Clades B and $\mathrm{E}$ isolates, respectively, this preference was not particularly observed for other clades [Moore et al., 1996]. Also, neutralization of primary isolates in these studies was sporadic, making interpretation difficult. Furthermore, few sera or isolates were derived from Clade Cinfected individuals. Recently [Bures et al., 2002], it was shown that Clade $\mathrm{C}$ sera neutralized autologous and heterologous Clade $\mathrm{C}$ isolates, including geographically diverse isolates. Selected sera displayed cross-clade neutralization activity against Clade B T-cell line adapted isolates (TCLA) and primary isolates. This suggests that antibody responses to Clade $\mathrm{C}$ infection may be capable of broad efficacy.

Taken together, these results suggest that there may be important differences in the presentation of HIV-1 antigens and epitopes to the immune system resulting in a different outcome in the immune response to Clade $\mathrm{C}$ infections. We have also shown that, in addition to clade-specific effects, there is heterogeneity of specific antibody responses to native primary viral isolates as a function of co-receptor usage [Cavacini et al., 2002]. Antibodies reactive with intact primary isolates have not been studied across clades. Therefore, we have analyzed antibody reactivity with and neutralization of primary isolate Clades $B$ and $C$ viruses using sera from individuals infected with Clade B virus and Clade $C$ virus. As described below, more robust antibody responses are observed among Clade C-infected patients; the antibodies were readily cross-reactive with Clades $\mathrm{B}$ and $\mathrm{C}$. The reciprocal cross-clade binding of Clade $\mathrm{B}$ antibodies to Clade $C$ viruses is less broad and less robust among the Clade B sera tested. These data suggest that studying the humoral immune responses of Clade $C$ patients may lead to more broadly reactive and effective antibodies for therapy and/or vaccine development.

\section{MATERIALS AND METHODS Clinical Samples and Virus}

Subtype B primary isolates, 92HT593, 92 US660 from N. Halsey, MACS, HIV-189.6 (89.6) from R. Collman, HIV1BAL (BAL) from S. Gartner, M. Popovic and R. Gallo, and subtype C primary isolate 93MW960 from Dr. Paolo Miotti and the UNAIDS Network for HIV Isolation and Characterization, and the DAIDS, NIAID were obtained through the AIDS Research and Reference Reagent Program, Division of AIDS, NIAID, NIH. Clade B X4 isolate 67970 was obtained from D. Montefiori, Duke University Medical School and Clade C R5 isolate 1157 was from the laboratory of Dr. Wood.

Informed consent was obtained from all participants in this study, and the study was approved by the institutional review boards of the Beth Israel Deaconess Medical Center and Fenway Community Health Center. Sera from Clade B-infected individuals were obtained from individuals seen either at the New England Deaconess Hospital, Boston MA (now Beth Israel Deaconess Medical Center) or the Fenway Community Health Center, Boston, MA for routine care. Sera were obtained from Clade C-infected individuals attending an HIV clinic at the University Teaching Hospital, in Lusaka, Zambia. While CD4 counts, anti-retroviral history, and probable seroconversion data were available for some of the Clade B-infected individuals, the ability to collect this information for the Clade C-infected individuals was not available at the time of this study. However, all individuals in this study were asymptomatic, without AIDS defining criteria, for a period of time prior to collection of the sera or plasma used in this study. While clade specificity for each individual in this study was not confirmed by sequencing viral isolates for each individual, the clade specificity for these cohorts has been established through other studies. For example, of the hundreds of isolates sequenced from the study site in Zambia, only two were not Clade $\mathrm{C}$ with one isolate being Clade $\mathrm{A}$ and another a Clade A/C recombinant. Similarly, with the rare exception of an individual being infected outside the United States (and who was not included in this study), sequence analysis of isolates from individuals seen at the study sites in Boston, especially in the time period that the samples were collected, has exclusively been Clade B.

\section{Reactivity With HIV-1 Infected Cells and Virions}

Serum IgG binding to primary HIV isolates was measured by ELISA as previously described [Cavacini et al., 1999]. Virus stocks were prepared in PHA-stimulated donor PBMC [Cavacini et al., 1998, 1999]. IgG in serum was captured onto ELISA plates coated with goat antihuman IgG (Fc specific) prior to the addition of virus stock diluted to $100 \mathrm{ng} / \mathrm{ml}$. The concentration of p24 released from bound virus by $1 \%$ triton was determined by ELISA. A cut-off value of $200 \mathrm{pg} / \mathrm{ml}$ is considered significant and serum from HIV seronegative donors captured less than $100 \mathrm{pg} / \mathrm{ml}$. Low levels of antibody are defined as $200-300 \mathrm{pg} / \mathrm{ml}$, moderate as $300-500 \mathrm{pg} / \mathrm{ml}$, and high titers as $>500 \mathrm{pg} / \mathrm{ml}$ of $\mathrm{p} 24$.

\section{Primary Isolate Neutralization Assays}

Primary isolate neutralization was measured using an assay that quantitates the amount of p24 produced by a constant inoculum of virus in PHA stimulated PBMC. In this assay, serum was diluted in growth media (RPMI 1640 with $20 \% \mathrm{FBS}$ and 5\% IL-2), and $50 \mathrm{ml}$ were added to $50 \mathrm{ml}$ of viral stock (200TCID50/ml) and incubated for $1 \mathrm{hr}$ at 378C. After $1 \mathrm{hr}$, donor PHA-stimulated PBMC (2 .105 cells) were added and the plates incubated for $2 \mathrm{hr}$ at 378C, 5\% CO2. The plates were washed twice, and the medium was replaced with fresh growth medium. Seven days after the infection was initiated, supernatant was 
removed and tested for p24 by ELISA. Serum from an HIV. seronegative person was included in each experiment, and the p24 values obtained with those samples were used to determine percent neutralization.

\section{RESULTS \\ Prevalence of Virion Specific Antibodies}

We have previously reported that the majority of individuals infected with Clade B HIV had either low or no serum IgG antibody reactive with native primary viral isolates [Cavacini et al., 1999]; furthermore, virion-specific antibody in Clade B sera correlated with CD4 counts and with neutralizing antibody activity. To further characterize the virion-specific and neutralizing antibody response, including the antibody response of individuals infected with Clade C HIV, we have analyzed sera from asymptomatic individuals infected with Clades B and C HIV without opportunistic infections, regardless of antiretroviral therapy. Since differential binding of human monoclonal antibodies had a virion dependency upon coreceptor usage [Cavacini et al., 2002], a total of seven isolates, including five Clade B and representing R5, R5X4, and $\mathrm{X} 4$ isolates and two Clade $\mathrm{C}$ isolates (both R5), were included in the analysis. Of the 32 asymptomatic Clade B-infected individuals, sera from all but one individual had specific antibody $(>200 \mathrm{pg} / \mathrm{ml})$ against at least one Clade B isolate of HIV (data not shown). Similarly, sera
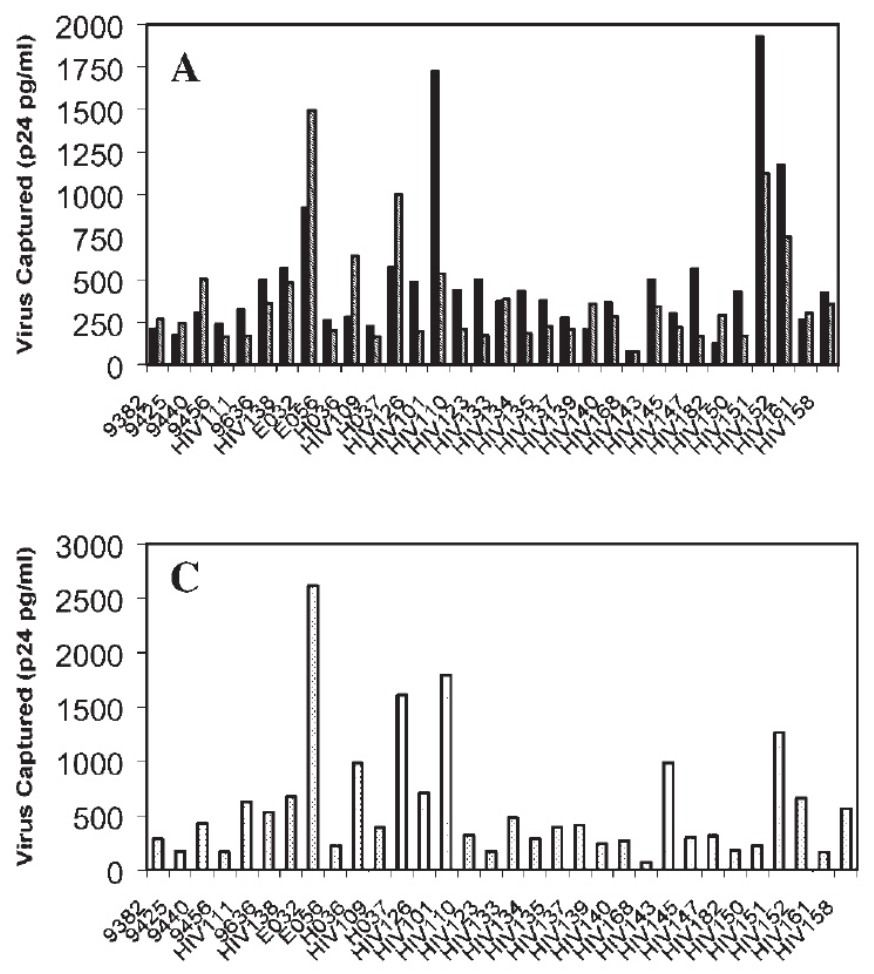

Fig. 1. Serum antibody reactive with $\mathrm{R} 5 \mathrm{X} 4$ and $\mathrm{X} 4$ primary isolate. IgG in sera from Clade $B(A, C)$ and Clade $C(B, D)$ infected individuals was diluted 1:50 and captured, in triplicate, onto ELISA plates using goat anti-human IgG, Fc-specific antibody. Unbound antibody was removed by washing prior to the addition of primary isolate virions from all but 2 of the 32 individuals infected with Clade C HIV had specific antibody reactive with at least one Clade C isolate of HIV (data not shown). Thus, consistent with our previous findings [Cavacini et al., 1999], asymptomatic HIV infection correlates with the presence of virion-specific antibody.

When tested for reactivity with R5X4 primary isolates 92HT593 and 89.6, a large number of sera from both Clade B (Fig. 1A) and Clade C (Fig. 1B) infected individuals were positive for virion-specific antibody. As summarized in Table I, $59 \%$ and $41 \%$ of sera from Clade Binfected individuals reacted with 92HT593 and 89.6, respectively, while $81 \%$ and $59 \%$ of Clade C sera were reactive with $92 \mathrm{HT} 593$ and 89.6 , respectively. These differences did not achieve statistical significance. Similarly, $59 \%$ of sera from Clade B and $84 \%$ of sera from Clade C-infected individuals reacted with the $\mathrm{X} 4$ isolate, 67970 (Fig. 1C,D). Although there were differences in the amount of p24 captured by individual sera, there was no statistically significant difference in the incidence of reactivity. The overwhelming majority of sera from both Clades B and C-infected individuals reacted with Clade B R5 isolates 92US660 and BaL (Fig. 2A,B). In sharp contrast, less than half of the Clade B sera (Fig. 2C) reacted with Clade C R5 isolate (1157 or 93MW960), while more than $80 \%$ of the Clade $\mathrm{C}$ reacted with Clade C virus (Fig. 2D). This was a statistically significant difference in reactivity against Clade $\mathrm{C}$ virus (Table I). It should be noted
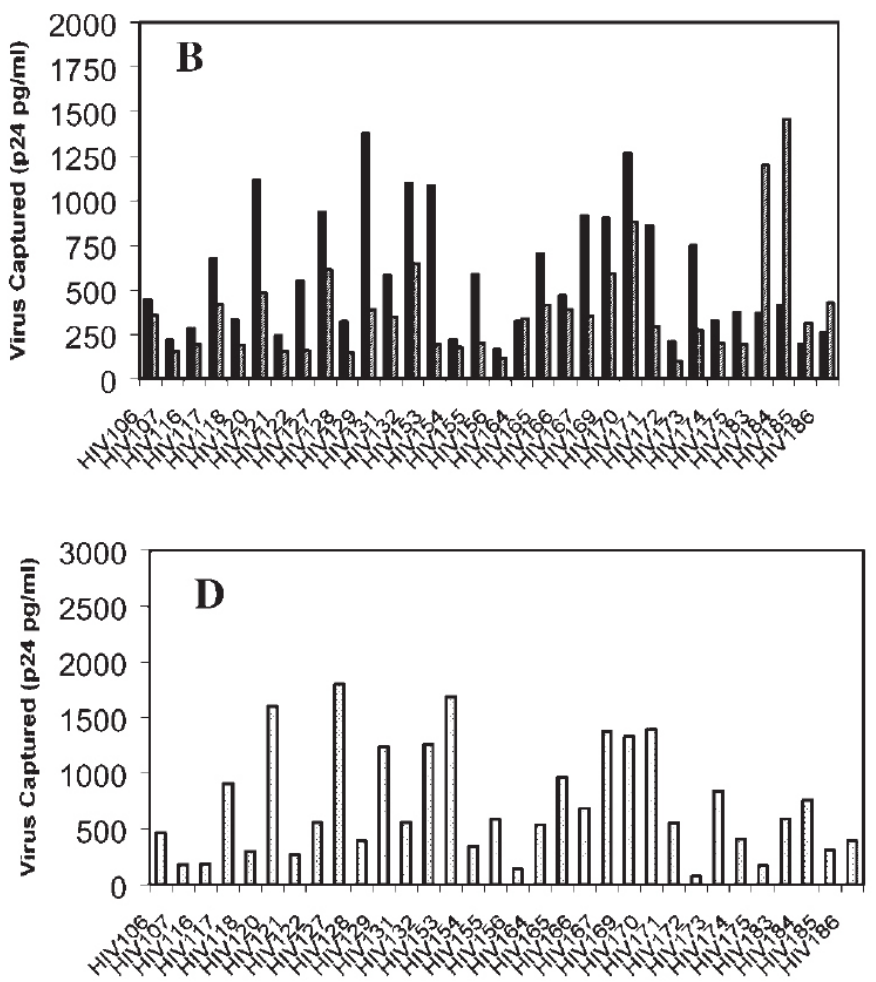

(100ng/ml p24). In (A) and (B), captured 92HT593 (solid bar) or 89.6 (slashed bar) and, in (C) and (D), captured 67970 virus were lysed using triton and released p24 quantitated by ELISA. Results are expressed as the $\mathrm{pg} / \mathrm{ml}$ of $\mathrm{p} 24$ released and represent the average of a minimum of three experiments. The cut-off for positive sera is $200 \mathrm{pg} / \mathrm{ml}$. 
TABLE I. Incidence of Serum IgG Exhibiting Virion Binding to Primary HIV Isolates

\begin{tabular}{|c|c|c|c|c|c|c|c|}
\hline & 92US660 & $\mathrm{BaL}$ & 93MW960 & 1157 & 92НТ593 & 89.6 & 67970 \\
\hline & Clade B, R5 & Clade B, R5 & Clade C, R5 & Clade C, R5 & $\begin{array}{c}\text { Clade B, } \\
\text { R5X4 }\end{array}$ & $\begin{array}{c}\text { Clade B, } \\
\text { R5X44 }\end{array}$ & Clade B, X4 \\
\hline Clade B Sera & $25 / 32(78 \%)^{a}$ & $25 / 32(78 \%)$ & $15 / 32(47 \%)$ & $10 / 21(48 \%)$ & $19 / 32(59 \%)$ & $13 / 32(41 \%)$ & $19 / 32(59 \%)$ \\
\hline Clade C Sera & $25 / 32(78 \%)$ & $28 / 32(88 \%)$ & $27 / 32(84 \%)$ & $17 / 21(81 \%)$ & $26 / 32(81 \%)$ & $19 / 32(59 \%)$ & $27 / 32(84 \%)$ \\
\hline$P$-value & $<0.3(\mathrm{NS})$ & $<0.3(\mathrm{NS})$ & $<0.02$ & $<0.02$ & $<0.2(\mathrm{NS})$ & $<0.4(\mathrm{NS})$ & $<0.2(\mathrm{NS})$ \\
\hline
\end{tabular}

NS, not statistically significant.

${ }^{a}$ Values represent number positive/total tested, with percent positive in brackets.

that fewer sera were analyzed for reactivity with Clade $\mathrm{C}$ isolate 1157 due to limited high-titered stocks of this isolate. However, the results obtained with 1157 were similar to that reported for 93MW960. Thus, the HIV antibody response of those infected with Clade C HIV displays broader cross-clade reactivity than the HIV antibody response of those infected with Clade B HIV. This is not a function of co-receptor usage as Clade B sera reacted equally well with R5 Clade B isolates as Clade C sera, yet had lower reactivity with R5 Clade $C$ isolates. Another indication of the difference in the breadth of reactivity is the observation that $34 \%$ (11 of 32 ) of Clade $B$ infected sera reacted with all isolates tested, whereas $56 \%$ (18 of 32) of Clade C-infected sera reacted with all isolates (data not shown).

Despite a difference in the incidence of reactivity between Clades B and C sera, analysis of the raw individual data (not shown) indicated that there is little difference
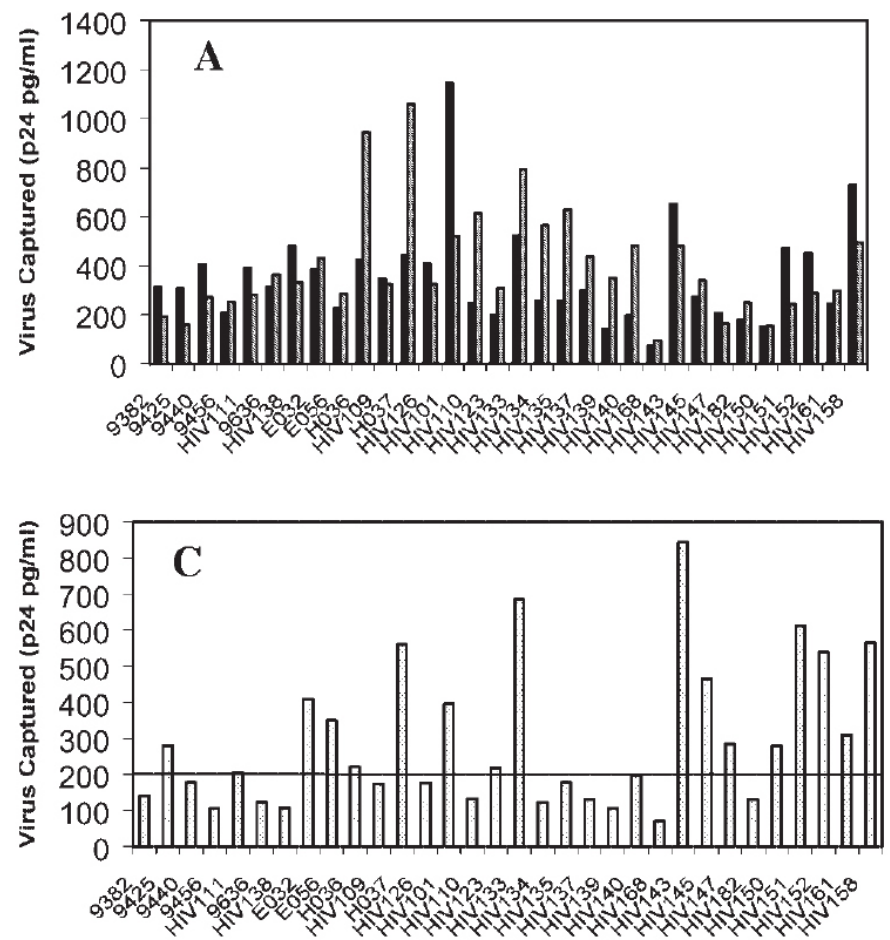

Fig. 2. Serum antibody reactive with R5 primary isolate virions. IgG in sera from Clade B $(\mathbf{A}, \mathbf{C})$ and Clade $\mathbf{C}(\mathbf{B}, \mathbf{D})$ infected individuals was diluted 1:50 and captured, in triplicate, onto ELISA plates using goat anti-human IgG, Fc-specific antibody. Unbound antibody was removed by washing prior to the addition of primary isolate virions $(100 \mathrm{ng} / \mathrm{ml}$ p24). In (A) and (B), captured clade B virus 92US660 (solid bar) or BaL in the amount of virus captured by sera for most isolates. Using the criteria of capture of more than $500 \mathrm{pg} / \mathrm{ml}$ as indication of high titer virion specific antibody, similar results were obtained with sera from both Clades $\mathrm{B}$ and C for isolates 92US660 (13\% for Clade B, 9\% for Clade C), 89.6 (22\% for Clade B, $19 \%$ for Clade C), BaL (22\% for Clade B, 31\% for Clade C), and 93MW960 (19\% for Clade B, 16\% for Clade C). For the R5X4 isolate 92HT593, more individuals infected with Clade C HIV (47\%) had high primary isolate-specific antibody than individuals infected with Clade B HIV (25\%). Similarly, 59\% of individuals infected with Clade $\mathrm{C}$ had high primary isolate-specific antibody reactive with the X4 isolate 67970, whereas fewer Clade B sera (38\%) had high specific antibody reactive with this isolate. Ten and 13 of the 32 individuals infected with Clade C or Clade B HIV, respectively, did not mount a high titer virion specific antibody response against any isolate.
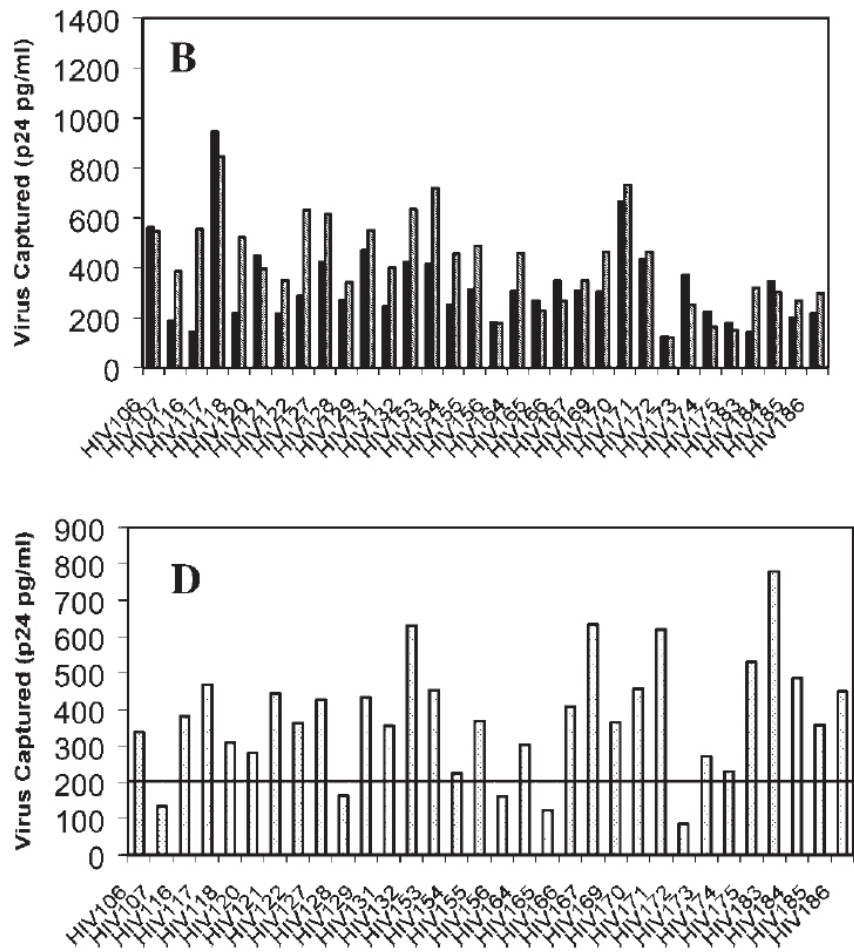

(slashed bar) and, in (C) and (D) captured Clade C 93MW960 virus were lysed using triton, and released p 24 was quantitated by ELISA. Results are expressed as quantity of p24 released in $\mathrm{pg} / \mathrm{ml}$ and represent the average of a minimum of three experiments. The cut-off for positive sera is $200 \mathrm{pg} / \mathrm{ml}$. 


\section{Neutralization of Primary Isolates by Sera}

Sera from HIV Clades B and C-infected individuals were tested for the ability to neutralize three Clade B (92HT593 \{R5X4\}, 92US660 \{R5\}, and $67970\{X 4\})$ isolates, and one Clade C (93MW960 \{R5\}) isolate. Values are expressed as the dilution of sera resulting in $90 \%$ neutralization (IC90). The higher the IC90 value, the more the sera can be diluted indicating more potent neutralizing activity. As shown in Table II, regardless of co-receptor use, there were no significant differences in neutralization between Clades B and C sera for the Clade B isolates. In contrast, there was a significant difference in the neutralization of Clade C. Sera from Clade B infected individuals did not neutralize Clade $C$ virus. In contrast, $40 \%$ of Clade $\mathrm{C}$ sera neutralized Clade $\mathrm{C}$ virus with a range of IC90 titers of 0-117 $(\mathrm{P}<0.04)$.

When neutralization titers and virion specific antibody are correlated, additional cross-clade differences are apparent. For the Clade B R5X4 isolate 92HT593, sera with virion-specific antibody had neutralization activity (IC90 > 10) as shown in Figure 3A. However for Clade B sera, the correlation was not tight. While neutralizing, a higher virion-specific antibody level did not necessarily indicate a greater neutralization activity. Similar results were obtained for Clade B sera and the Clade B R5 isolate 92US660 (Fig. 3B). Moreover, despite high HIV specific antibody, only a quarter of the Clade $\mathrm{C}$ sera with virion-specific antibody neutralized 92US660 (Fig. 3B). Also, only half of Clade B or C sera with virion-specific antibody neutralized the $\mathrm{X} 4$ isolate 67970 (Fig. 3C) and none of the Clade B sera neutralized Clade $C$ R5 virus 93MW960 (Fig. 3D), despite more than $40 \%$ of the sera having virion specific antibody. In addition, only half of the virion specific antibody positive Clade $C$ sera neutralized Clade C virus. Despite a lack of direct correlation between the concentration of virion specific antibodies and neutralization titers, with the exception of two sera with the Clade B R5 isolate, 92US660, all neutralizing sera had virion-specific antibodies. Thus, while the presence of virus-specific antibody did not predict neutralization activity, specific antibody was essential for neutralization activity to be present in the sera. This implies that some virus-specific antibody is not directed at neutralizing epitopes.

\section{DISCUSSION}

We have shown previously that the majority of individuals infected with Clade B HIV had either low or no serum IgG antibody reactive with native primary isolate virions [Cavacini et al., 1999]. In this report, we studied virus-specific antibodies from asymptomatic individuals infected with either Clade B or C HIV, and cross-clade virion binding and neutralization by serum antibodies from these two populations. Consistent with our previous report, native virion-specific antibody was necessary for viral neutralization, albeit it did not predict neutralization activity. That is, sera with robust neutralization activity had viral specific antibody, while only some sera with virus-specific antibody had neutralizing antibody. It is not surprising that among the multiple assays and individuals studied, there are rare individuals with low titers of virion specific antibody but with high levels of neutralizing antibody to an individual isolate. This can be explained by heterogeneity in both the polyclonal antibody response and virus (autologous virus vs. test virus in assay).

It has been suggested that the failure of most neutralizing human monoclonal antibodies to react substantially with native primary viral isolates is the result of non-functional spikes on the virons suggesting that the viral capture assay is a limited assay for the study of antibody/viral interactions resulting in viral neutralization [Poignard et al., 2003]. However, it can be argued that the utility of the viral capture assay is a function of the parameters of the assay [Cavacini and Posner, 2004]. For example, differences in the incorporation of specific cellular host components in the viral membrane as a function of the cell type used to produce progeny virus has major implications for infectivity, gp120/41 structure, and viral neutralization. More importantly, the use of a neutralizing antibody to capture virus has been shown to result in reduced viral output, which is to be expected, and which may influence interpretation of the results. Failure of neutralizing antibodies to bind substantially to primary isolate virions may reflect virion camouflage. Non-V3 neutralizing epitopes are not exposed on the primary HIV isolates until the virus is in proximity of a target cell or in the post-CD4 binding state. Further, the immune system is confounded by the immunogenicity of

TABLE II. Neutralization of Primary Isolates by HIV Sera

\begin{tabular}{|c|c|c|c|c|}
\hline & \multicolumn{4}{|c|}{ Average $\mathrm{IC}_{90}{ }^{\mathrm{a}}$} \\
\hline & 92US660 & 92НТ593 & 67970 & 301960 \\
\hline & Clade B, R5 & Clade B, R5X4 & Clade B, X4 & Clade C, R5 \\
\hline Clade B Sera & $88(2-235)$ & $79(2-257)$ & $27(0-106)$ & $0.3(0-2)$ \\
\hline Clade C Sera & $44(0-331)$ & $78(0-207)$ & $23(0-88)$ & $27(0-117)$ \\
\hline$P$-value ${ }^{\mathrm{b}}$ & $<0.2$ & $<0.5$ & $<0.4$ & $<0.04$ \\
\hline
\end{tabular}

${ }^{a}$ Values represent the reciprocal dilution of the average $\mathrm{IC}_{90}$ value for each group with the range in parentheses.

${ }^{\mathrm{b}}$ Significance of difference between Clades B and C sera for each isolate was determined by Student's $t$-test. 

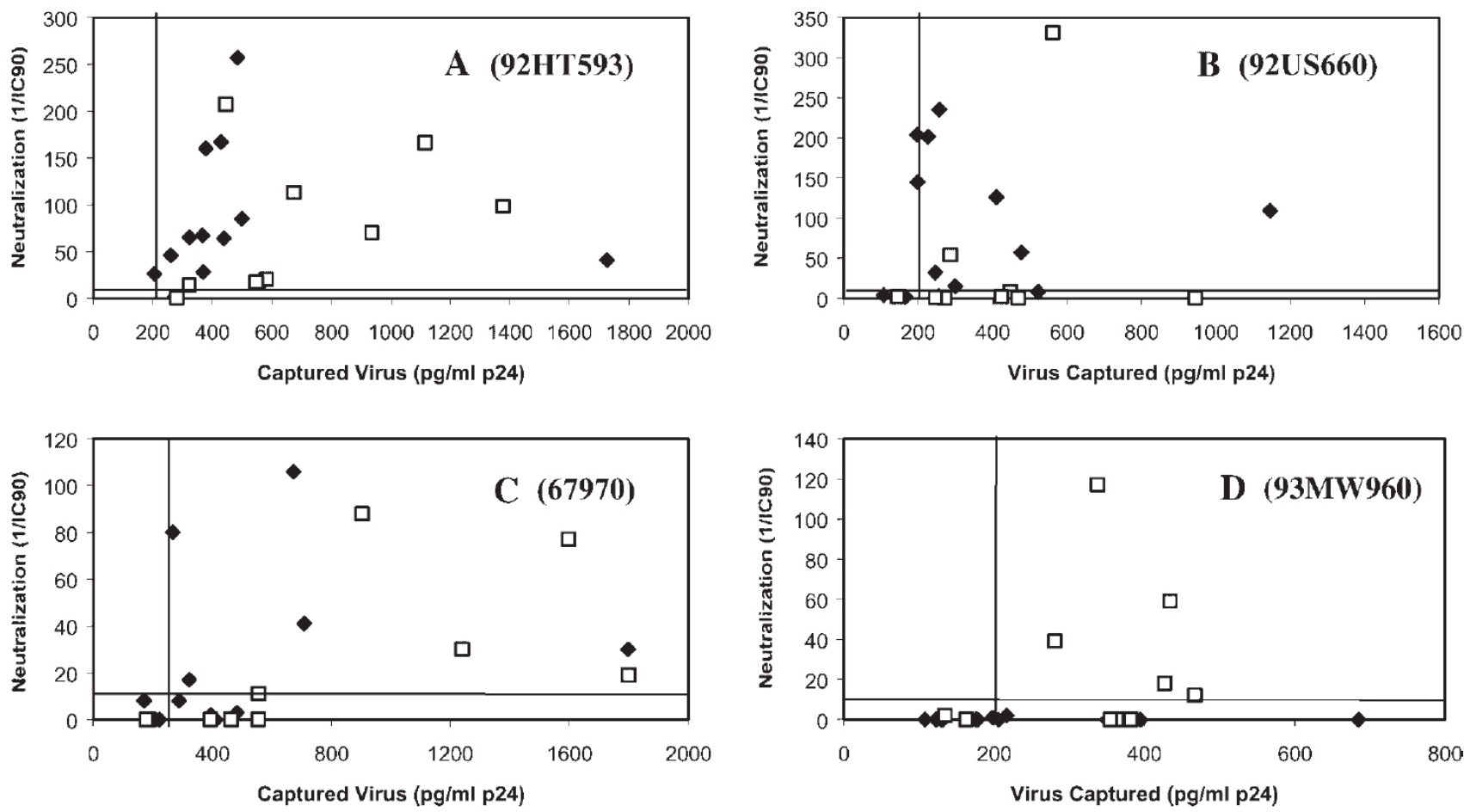

Fig. 3. Relationship of virion-specific antibody with viral neutralization. For each serum, virion-specific antibody, as $\mathrm{pg} / \mathrm{ml}$ of $\mathrm{p} 24$, is plotted on the $\mathrm{x}$-axis as a function of the reciprocal dilution of the $\mathrm{IC}_{90}$ value for neutralization. Isolate 92HT593 is shown in (A), $92 \mathrm{US660}$ in (B), $67970 \mathrm{in}(\mathbf{C})$, and 93MW960 in (D). Closed symbols represent Clade B sera and open symbols represent Clade $\mathrm{C}$ sera. The vertical line represents the cut-off for positive virion specific antibody $(200 \mathrm{pg} / \mathrm{ml})$ and the horizontal line represents the cut-off for neutralization activity (10).

the exposed variable loops while neutralizing epitopes are not generally available to immune cells or serum antibody. For those sera with both high virion binding antibody and neutralization, it can be hypothesized that V3 loop antibody, which readily reacts with virions, is a major contributor to virion binding and neutralization for these sera. Further analysis of the epitopes recognized by the antibodies that capture virus, and the contribution of those antibodies to in vivo viral inactivation or neutralization are underway. Finally, the contribution of synergy between non-neutralizing serum antibodies, which bind primary HIV isolates and neutralizing antibodies in in vitro viral neutralization remains to be determined, although synergy in this setting has been demonstrated for human monoclonal antibodies [Cavacini et al., 2002].

Antibodies raised in response to HIV-1 vaccines in humans and animals react with HIV but rarely neutralize primary isolates [Mascola et al., 1996; Beddows et al., 1999; Bures et al., 2000]. Early reports suggested that there is no strict clade dependence of neutralization [Kostrikis et al., 1996; Moore et al., 1996; Nyambi et al., 1996; Weber et al., 1996]. In this study, serum antibodies in Clade C-infected individuals reacted with Clade C HIV as well as crossreacted with Clade B HIV. However, virion-reactive antibodies in individuals infected with Clade B HIV were not as robustly cross-reactive with Clade C HIV. Consistent with this result, sera from Clade C-infected individuals have been shown to broadly neutralize autologous and heterologous Clade C isolates and Clade B isolates [Bures et al., 2002]. Of interest, it has been reported that a disproportionate number of African women, as compared to African men and European men and women, had high-titer, broadly cross-reactive neutralizing antibodies [Beirnaert et al., 2000; Donners et al., 2002].

In conclusion, there is a significant difference in the quality of the humoral response to Clade $C$ virus compared to Clade B virus. Antibodies from individuals infected with Clade C HIV-1 have broader cross-reactivity in both primary virion binding and neutralizing activity than antibodies from individuals infected with Clade B HIV. Further study of the humoral response of Clade C infected individuals, in terms of antibody reactivity and presentation of viral epitopes to the immune system, may lead to more broadly reactive and effective antibodies for therapy and/or vaccine development.

\section{ACKNOWLEDGMENTS}

The authors are grateful to the participants in the study for their time and dedication to the research.

\section{REFERENCES}

Arora P, Cyriac A, Jha P. 2004. India's HIV-1 epidemic. CMAJ 171: 1,337-1,338.

Beddows S, Lister S, Cheingsong R, Bruck C, Weber J. 1999. Comparison of the antibody repertoire generated in healthy 
volunteers following immunization with a monomeric recombinant gp120 construct derived from a CCR5/CXCR4using human immunodeficiency virus type 1 isolate with sera from naturally infected individuals. J Virol 73: 1,7401,745 .

Beirnaert E, Nyambi PN, Willems B, Heyndrickx L, Colebunders R, Janssens W, van der Groen G. 2000. Identification and Characterization of sera from HIV-infected individuals with broad cross-neutralizing activity against Group M (env clade A-H) and Group O primary HIV-1 isolates. J Med Virol 61: 14-24.

Betts M, Krowka J, Santamaria C, Balsamo K, Gao F, Mulundu G, Luo C, N'Gandu N, Sheppard H, Hahn B, Allen S, Frelinger J. 1997. Cross-clade human immunodeficiency virus (HIV)-specific cytotoxic T-lymphocyte responses in HIV-infected Zambians. J Virol 71: 8,908-8,911.

Bures R, Gaitao A, Zhu T, Graziosi C, McGrath K, Tartaglia J, Caudrelier P, Habib RE, Klein M, Lazzarin A, Stablein D, Deers M, Corey L, Greenberg M, Schwartz D, Montefiori D. 2000. Immunization with recombinant canarypox vectors expressing membrane-anchored gp120 followed by gp160 protein boosting fails to generate antibodies that neutralize R5 primary isolates of human immunodeficiency virus type 1. AIDS Res Hum Retroviruses 16: 2,019-2,035.

Bures R, Morris L, Williamson C, Ramjee G, Deers M, Fiscus SA, Abdool-Karim S, Montefiori DC. 2002. Regional clustering of shared neutralization determinants on primary isolates of clade $C$ human immunodeficiency virus type 1 from South Africa. J Virology 76: 2,233-2,244.

Cao H, Kanki P, Sankale J, Dieng-Sarr A, Mazzara G, Kalams S, Korber B, Mboup S, Walker B. 1997. Cytotoxic T-lymphocyte cross-reactivity among different human immunodeficiency virus type 1 clades: Implication for vaccine development. J Virol 71: 8,615-8,623.

Cavacini L, Posner M. 2004. Native HIV-1 virion surface structures: Relationships between antibody binding and neutralization or lessons from the viral capture assay. AIDS Res Hum Retroviruses 20: 435-441.

Cavacini L, Samore M, Gambertoglio J, Jackson B, Duval M, Wisnewski A, Hammer S, Koziel C, Trapnell C, Posner M. 1998. Phase I study of a human monoclonal antibody against the CD4 binding site of HIV-1/gp120. AIDS Res Human Retrovirus 14: 545-550.

Cavacini L, Peterson J, Nappi E, Duval M, Goldstein R, Mayer K, Posner M. 1999. Minimal incidence of serum antibodies reactive with intact primary isolate virions in HIV-1 infected individuals. J Virol 73: 9,638-9,641.

Cavacini L, Duval M, Robinson J, Posner M. 2002. Interactions of human monoclonal antibody combinations, epitope exposure and antibody binding to intact primary isolate virons and the relationship to neutralization. AIDS 16: 2,4092,417 .
Donners H, Willems B, Beirnaert E, Colebunders R, Davis D, van der Groen G. 2002. Cross-neutralizing antibodies against primary isolates in African women infected with HIV-1. AIDS 16:501-503.

Essex M. 1993. State of the HIV pandemic. J Human Virol 1: 427429.

Ferrari G, Humphrey W, McElrath M, Excler J, Dluiege A, Clements M, Corey L, Bolognesi D, Weinhold K. 1997. Clade B based HIV-1 vaccines elicit cross-clade cytotoxic T lymphocyte reactivities in uninfected volunteers. Proc Natl Acad Sci 94: 1,396-1,401.

Kostrikis L, Cao Y, Ngai H, Moore J, Ho D. 1996. Quantitative analysis of serum neutralization of human immunodeficiency virus type 1 from subtypes A, B, C, D, E, F, and I: Lack of direct correlation between neutralization serotypes and genetic subtypes and evidence for prevalent serum-dependant infectivity enhancement. J Virol 70: 445-458.

Mascola J, Snyder S, Weislow O, Belay S, Belshe R, Schwartz D, Clements M, Dolin R, Graham B, Gorse G, Keefer M, McElrath J, Walker M, Wagner K, McNeil J, McCutchan F, Burke D. 1996. Immunization with envelope subunit vaccine products elicits neutralizing antibodies against laboraory-adapted but not primary isolates of human immunodeficiency virus type 1. J Infect Dis 173: 340-348.

Moore J, Cao Y, Leu J, Qin L, Korber B, Ho D. 1996. Inter-and intraclade neutralization of human immunodeficiency virus type 1: genetic clades do not correspond to neutralization serotypes but partially correspond to gp120 antigenic serotypes. J Virol 70: 427-444.

Nyambi PN, Nkengasong J, Lewi P, Andries K, Janssens W, Fransen K, Heyndrickx L, Piot P, Groen Gvd. 1996. Multivariate analysis of human immunodeficiency virus type 1 neutralization data. J Virol 70: 6,235-6,243.

Oelrichs R, Shrestha I, Anderson D, Deacon N. 2000. The explosive human immunodeficiency virus type 1 epidemic among injecting drug users of Kathmandu, Nepal, is caused by a subtype $C$ virus of restricted genetic diversity. J Virol 74: 1,149-1,157.

Poignard P, Moulard M, Golez E, Vivona V, Franti M, Venturini S, Wang M, Parren P, Burton D. 2003. Heterogeneity of envelope molecules expressed on primary human immunodeficiency virus type 1 particles as probed by the binding of neutralizing and nonneutralizing antibodies. J Virol 77: 353-365.

Spira S, Waiberg M, Loemba H, Turner D, Brenner B. 2003. Impact of clade diversity on HIV-1 virulence, antiretroviral drug sensitivity and drug resistance. J Antimicrob Chemother 51: 229-240.

Weber J, Fenyo E-M, Beddows S, Kalefbu P, Bjorndal A, Characterization WNfHIa. 1996. Neutralization serotypes of human immunodeficiency virus type 1 field isolates are not predicted by genetic subtype. J Virol 70: 7,827-7,832. 